
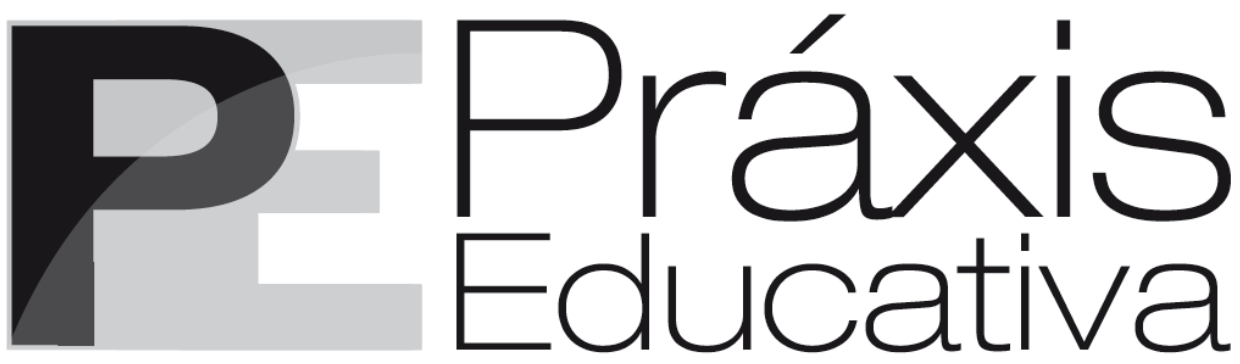

ISSN 1809-4309 (Versão online)

DOI: 10.5212/PraxEduc.v.12i2.0002

Educação Física: formação de professores e inclusão

Physical Education: teacher training and inclusion

Educación Física: formación de profesores e inclusión

David Rodrigues*
Luzia Lima-Rodrigues

Resumo: A formação de professores, para dinamizarem e atuarem em contextos educacionais inclusivos, é um assunto da maior relevância. Vários autores têm chamado a atenção para a importância da formação nos valores e nas práticas dos professores. Neste artigo, procuramos problematizar essa formação tendo em atenção os valores prevalentes e dominantes da área da Educação Física. Discutimos as suas dificuldades específicas que se prendem a uma exacerbada meritocracia e a raras práticas de diferenciação e adaptação curricular. Este texto inclui, ainda, um testemunho, "na primeira pessoa", de uma professora de Educação Física com condição de deficiência, em que é realçada a influência da formação que recebeu na formação que ministra.

Palavras-chave: Educação Inclusiva. Educação Física. Formação de professores.

Abstract: The teachers' training to dynamize and to act in inclusive educational contexts, is a matter of major relevance. Several authors have drawn attention to the importance of education in teachers' values and practices. In this paper, we seek to problematize this education taking into account the prevalent and dominant values of Physical Education. We discuss their specific difficulties that are related to an exacerbated meritocracy and rare practices of differentiation and curricular adaptation. This text also includes a testimony 'in the first person' of a Physical Education teacher with a deficiency condition in which she emphasizes the influence of the education she received in the education she provides.

Keywords: Inclusive Education. Physical Education. Teacher training.

Resumen: La formación de profesores, para dinamizar y actuar en contextos educativos inclusivos, es un asunto de gran relevancia. Varios autores han llamado la atención sobre la importancia de la formación en los valores y en las prácticas de los profesores. En este trabajo se intenta problematizar dicha formación, teniendo en cuenta los valores predominantes y dominantes del área de Educación Física. Se discuten sus dificultades específicas relacionadas con la meritocracia exagerada y prácticas raras de diferenciación y la adaptación curricular. Este texto también incluye un testimonio, "en primera persona", de una profesora de Educación Física con condición de deficiencia en la que se destaca la influencia de la formación que recibió en la capacitación que administra.

Palabras clave: Educación Inclusiva. Educación Física. Formación de profesores.

\footnotetext{
* Professor do Instituto de Educação - Universidade de Lisboa. E-mail: <drodrigues@fmh.ulisboa.pt>.

** Professora do Instituto Politécnico de Setúbal. E-mail: <luzia@vindas.pt>.
} 


\title{
Introdução
}

\begin{abstract}
A Educaşão Física Inclusiva reconhece o valor intrínseco de cada aluno, o seu direito de assumir riscos e de cometer erros, a sua necessidade de independência, de auto-determinação e o direito de escolha.
\end{abstract}

(NATIONAL Education Steering Committee of the Moving to Inclusion Initiative, 1994, s.p., tradução nossa).

A Inclusão de alunos nas escolas regulares tornou-se uma tendência mundial. Assistiu-se, a partir dos anos 80 e 90 do século passado, a um movimento de "integração" de alunos com condição de deficiência na escola regular. Esse movimento assumiu-se como muito interessante. Podemos encontrar vários aspectos inovadores:

a) Antes de mais, foi a primeira vez que muitas escolas foram frequentadas por alunos com condição de deficiência. Em termos históricos, a escolarização desses alunos não é muito fértil em sucessos... ficavam muitas vezes privados da frequência à escola, entregues aos cuidados domésticos da família ou de instituições de cariz assistencial. Só na segunda metade do século 20, é que começaram a ser disseminadas as instituições de Educação Especial que, juntamente a aspectos mais assistenciais, proporcionavam a possibilidade de uma escolarização. Essa organização, que segregava as crianças com condição de deficiência, encarando-as como ineducáveis ou como somente capazes de desempenhos muito elementares, perdurou praticamente até os nossos dias. O movimento "integrativo" proporcionou às escolas um primeiro contacto com os alunos com deficiência, sobretudo com as suas capacidades de escolarização, e deu provas de que valia a pena ter expectativas sobre o progresso escolar dessa população.

b) Outro aspecto foi que o movimento integrativo permitiu pensar em "escolas acessíveis" em termos arquitectónicos e, ainda que as mudanças curriculares fossem muito tímidas, algumas estratégias (e.g., mais tempo para aprendizagem, possibilidade de outra organização escolar, acesso a professores de apoio etc.) e materiais (sobretudo para alunos com deficiência visual e motora) passaram a ser património habitual da escola regular.

c) Por fim, a presença de alunos com condição de deficiência na escola regular permitiu confirmar que a educação desses alunos, em ambientes mais diversos e, portanto, mais estimulantes, poderia contribuir para atingir objectivos mais ambiciosos. Essa confirmação foi abrangente e transversal a todos os que participam, directa ou indirectamente, do processo educativo dentro da escola (alunos sem deficiência, gestores, professores etc.) e fora dela (pais, responsáveis comunitários etc.).

O desenvolvimento de práticas integrativas mostrou também que era preciso ir mais longe. O facto de assumir-se que todas as pessoas que tinham uma condição de deficiência tinham Necessidades Educativas Especiais levou a que todo o apoio e todo o potencial de diversidade e de flexibilização da escola se situassem em alunos com condição de deficiência. Ora, situar os recursos da escola exclusivamente nesses alunos levanta dois problemas: por um lado, nem todos os alunos com condição de deficiência precisam de um atendimento específico na escola; por outro lado, existem alunos que precisariam de um atendimento especializado mas que, por não terem uma condição de deficiência identificada, não podem usufruir desse atendimento. 
A perspectiva "integrativa" não se centrava na modificação de aspectos centrais do currículo como, por exemplo, os objectivos ou os conteúdos, mas somente em formas diferenciadas de se chegar às mesmas metas. Existe uma filosofia meritocrática nessa visão, dado que se entende que essas pequenas alterações conseguiriam colocar os alunos com condição de deficiência em igualdade de oportunidades com os restantes. E se não conseguissem... bem... isso significaria que, "depois de se ter feito o possível", o aluno poderia ser "devolvido" para uma situação "menos integrativa", como uma escola especial, por exemplo. Ficar-se-ia com a consciência de que essa desistência se devia à falta de competências do aluno, na certeza de que a escola tinha feito o esforço integrativo possível.

Nesse período, a formação de professores reflectia essa realidade. Os professores eram formados para seguir um currículo único e a sua formação em Necessidades Educativas Especiais era irrisório ou inexistente. Se consultarmos os planos curriculares dos anos de 1980 e 1990, verificaremos que, nos cursos regulares de formação de professores (salvo raras excepções), não existiam disciplinas sobre Necessidades Educativas Especiais. Ou, então, quando existiam, centravam os seus conteúdos na caracterização biomédica das deficiências, produzindo um impacto muito reduzido no desenvolvimento de competências para a "integração". Com isso, os professores encontravam na escola a (in)formação de que precisavam, normalmente transmitida por outros técnicos e posta em prática por "tentativa e erro".

A perspectiva inclusiva que começa a tomar forma a partir de meados dos anos de 1990 vem a ser um rompimento com a perspectiva integrativa. A tão conhecida Declaração de Salamanca (UNESCO, 1994) defende radicalmente que:

[...] as escolas regulares, seguindo esta orientação inclusiva, constituem os meios mais capazes para combater as atitudes discriminatórias, criando comunidades abertas e solidárias, constituindo uma sociedade inclusiva e atingindo a educação para todos [...]. (UNESCO, 1994, p. 1).

Assim, na perspetiva inclusiva, a presença de alunos com condição de deficiência na escola deixa de ser uma experiência "bacana", passando a ser a forma mais adequada e mais capaz para a sua educação. A escola regular assume-se como responsável pela educação de todas as crianças que a frequentam. Essa responsabilidade implica que não existe mais a possibilidade de "devolvê-las" a ambientes mais restritivos, quaisquer que sejam os motivos evocados (nomeadamente a deficiência). Em um estudo que realizamos sobre os percursos de Educação Inclusiva de 10 escolas portuguesas (LIMA-RODRIGUES et al., 2007), a totalidade dos professores entrevistados considerou que o encerramento da escolarização dos alunos com condição de deficiência em escolas especiais, trazendo-os para as escolas regulares (Portugal tem, hoje, 97\% de Inclusão), serviu para os obrigar a rever as suas culturas e as suas práticas educativas, "empurrando-os" em direcção a pedagogias mais inclusivas.

Como é óbvio, o movimento da Educação Inclusiva não podia deixar de influenciar os cursos de formação de professores, e fê-lo de várias formas. O resultado mais evidente foi a proliferação da oferta de disciplinas obrigatórias e opcionais sobre "Necessidades Educativas Especiais"/“Educação Especial"/“Dificuldades de Aprendizagem”. Esses cursos têm procurado uma maior adequação à diversidade de alunos que frequentam a escola pública, ao introduzirem conteúdos como "atendimento à diversidade", "educação multicultural", "flexibilização curricular" etc. Vivemos, em 2010, em uma atmosfera muito estimulante em que surgem (e são discutidas) soluções, conteúdos e experiências que poderão preparar melhor os professores para trabalharem com alunos com condições de deficiência e Necessidades Educativas Especiais, em um ambiente inclusivo. 
Apesar de estimulante, esse período é também polémico face à falta de coerência existente entre as novas necessidades de formação dos professores e as respostas ainda tradicionais dadas pelos cursos de formação. Há, assim, uma necessidade dos formadores reverem os seus programas de formação para poderem tornar os professores aptos para encarar os desafios da Inclusão. Ainda que exista uma unanimidade à volta da necessidade de desenvolver uma formação sobre Educação Inclusiva, não se verifica, na prática, uma organização temporal e de conteúdos coerente com essa necessidade (VICKERMAN, 2007).

O tema central deste capítulo é a discussão de como esses valores e modelos têm chegado à formação de professores de Educação Física.

\section{Conceito de Educação Inclusiva}

O conceito de Inclusão é complexo e vasto, tal como se pode constatar pela multiplicidade de definições produzidas. Em 2008, a UNESCO publicou um importante documento que colocou o conceito de Inclusão alicerçado em quatro referenciais:

a) A Inclusão é um processo. Não é, portanto, algo definitivo, que se tem ou que se é. É um percurso que a escola faz e que pode aproximá-la ou afastá-la mais do objectivo de uma escola que seja de (e para) todos e de (e para) cada um.

b) A Inclusão diz respeito à identificação e remoção de barreiras. O trabalho centrado na identificação de barreiras à aprendizagem é muito interessante e exige dinamismo. Remover barreiras à aprendizagem não é sinónimo de tornar a aprendizagem "fácil" ou "sem esforço". Claro que todos gostaríamos que a aprendizagem fosse fácil e óbvia, mas não é: toda a aprendizagem, para atingir a mestria, exige esforço e motivação. Assim, remover barreiras significa, sobretudo, que identificamos e removemos tudo o que, não fazendo parte da aprendizagem, pode dificultá-la. Por exemplo: quantos professores exigem aos alunos que uma prova seja feita dentro de um determinado tempo? Resposta: quase todos. Nova pergunta: o tempo restrito da prova pode ser uma dificuldade? Resposta: muitas vezes. No entanto, temos de pensar que há alunos que, ao gerirem mal o tempo de dar respostas, obtêm maus resultados nas provas. O facto de um aluno ser mais lento ou mais rápido ao elaborar as respostas não tem nada a ver com o conhecimento que ele construiu sobre o assunto questionado. Então, será que o tempo exigido não pode ser uma "barreira", dificultando que o aluno seja avaliado justamente? Esse é só um exemplo, mas muitos mais poderiam ser identificados e removidos.

c) A Inclusão refere-se à presença, à participação e ao sucesso de todos. A Educação Inclusiva não se esgota apenas na presença nem na participação, mas refere-se também ao sucesso de todos os alunos no processo educativo. Isso quer dizer que o insucesso de um aluno é também o insucesso da escola. Nesse sentido, a expressão "sucesso de todos" é radical porque não abre excepções.

d) Inclusão centra-se nas pessoas em risco de marginalização, exclusão ou insucesso. É certo que a Educação Inclusiva se destina a todos e a cada um dos alunos da escola. Como se tem afirmado repetidamente, espera-se que as soluções encontradas para as dificuldades de aprendizagem de um aluno possam ser estimulantes para a aprendizagem de todos os outros. Não obstante a Educação Inclusiva destine-se a TODOS os alunos (porque todos são diferentes), existe em paralelo uma atenção particular àqueles que estão em maior risco por não terem sucesso, por serem marginalizados ou excluídos da escola. Sem um maior direcionamento de atenção, recursos e meios para esses alunos, há pouca possibilidade de que continuem na escola.

Práxis Educativa, Ponta Grossa, v. 12, n. 2, p. 317-333, maio/ago. 2017 Disponível em: <http://www.revistas2.uepg.br/index.php/praxiseducativa > 
$\mathrm{Na}$ Convenção sobre os Direitos das Pessoas com Deficiência (ONU, 2006), é assumido que a educação das pessoas com deficiência se deve passar em um ambiente inclusivo. No artigo $24\left(\$ 2^{\circ}\right)$, encontramos que, para realizar o direito à Educação, os Estados Membros devem assegurar que:

\begin{abstract}
a) as pessoas com deficiência não sejam excluídas do sistema regular de educação por motivo da sua deficiência e que as crianças com deficiência não são excluídas da educação básica obrigatória e gratuita, ou da educação secundária, por motivo da sua deficiência;

b) as pessoas com deficiência possam ter acesso a uma educação primária e secundária inclusiva, de qualidade e gratuita numa base de igualdade com as outras crianças da comunidade em que vivem. (ONU, 2006, p. 11).
\end{abstract}

Trata-se, pois, de uma reforma educacional que promove a educação conjunta de todos os alunos, independentemente das suas capacidades, estatuto socioeconómico ou outras características. Essa reforma tem por objetivo modificar as práticas educacionais tradicionais, removendo as barreiras e promovendo a aprendizagem de todos (RODRIGUES, 2007).

Existem vários aspectos do conceito de Educação Inclusiva que constituem verdadeiras "revoluções" nas concepções da escola tradicional. Pensar que se deve trabalhar (sem desistir) para que todos os alunos possam ter sucesso, pensar que a exclusão e o insucesso são uma derrota para a escola, pensar que todos os alunos (independentemente do seu nível de aprendizagem, comportamento ou capacidades) devem aprender em conjunto, são conceitos talvez mais fáceis de enunciar do que consumar. Dentre os recursos que podem contribuir para tornar essa reforma possível é frequentemente apontada a formação de professores.

\title{
Formação de professores e Inclusão
}

Espera-se que uma formação de professores para a Inclusão prepare os formandos não só para participarem no movimento da Inclusão (contribuírem com boas práticas em uma perspectiva inclusiva) mas também para que possam ser, eles próprios, os reformadores ou inovadores da escola onde actuam, incentivando, encorajando e motivando a transformação rumo a valores e práticas mais inclusivos. Para isso, no âmbito dos cursos de formação de professores, há de se saber muito bem "quem reforma os reformadores" e "como" o fazem. É que não existe uma "metafísica" da formação em que o professor se transforma em um "inovador" por pura "magia", se ele não for formado e preparado para isso.

A formação de professores é um caminho que se desenvolve por meio de dilemas. Em um dilema, não é a opção "a" ou "b" que está certa, mas é uma questão de optar pelo erro que nos parece menor. Referiríamos alguns aspectos que nos parecem centrais para a discussão sobre a formação de professores para a Inclusão, constituindo-se cada um deles como um dilema uma opção que, em princípio, não está certa ou errada.

\section{a) Dimensão dos modelos de formação}

Como já foi dito, os conteúdos relacionados à educação de alunos com deficiência foram sendo contemplados de várias formas nos cursos de formação de professores. No modelo mais comum, foram introduzidas disciplinas com o objectivo de dar a conhecer as características dos alunos com condição de deficiência, a forma como aprendem e os aspectos metodológicos específicos a considerar. Para além desse modelo, existe um outro, já menos comum, denominado por "infusão" (KOWALSKY, 1995): trata-se da disseminação dos conteúdos 
relativos à educação de alunos com condições inabituais de desenvolvimento e aprendizagem por todas as disciplinas do curso.

\begin{abstract}
A informação sobre as deficiências transmitidas por uma única disciplina, se não for ensinada através da "infusão", pode facilmente ser percepcionada pelos estudantes como isolada e sem significado. Como resultado de experiências de infusão, os estudantes são estimulados de uma forma permanente para assimilar e aplicar o conhecimento sobre a deficiência no seu ensino e, desta forma, permite elevar o seu nível de compromisso". (KOWALSKI, 1995, p. 55).
\end{abstract}

Além da maior motivação e do comprometimento dos estudantes, destacaríamos duas outras considerações sobre a "infusão": em primeiro lugar, é muito difícil abordar, por exemplo, as teorias de aprendizagem sem referir as dificuldades de aprendizagem, assim como ensinar Psicologia do Desenvolvimento sem estudar os casos em que o desenvolvimento, pela ocorrência de uma deficiência ou outra razão qualquer, ocorreu de forma diferente - estas são situações onde a "infusão" nos parece inevitável. Em segundo lugar, a "infusão" configura-se como uma forma "inclusiva" de abordar os temas ensinados na formação de professores, dado que não se cria uma divisão entre o currículo, o desenvolvimento e a aprendizagem ditos "normais" e "especiais", da mesma forma que o modelo inclusivo não categoriza os alunos em "normais" e "especiais".

A investigação sobre esses dois modelos de formação não é conclusiva sobre a superioridade de nenhum deles. Em um estudo realizado com 603 professores de quatro países, Sharma, Forlin e Loreman (2008) concluem que tanto o modelo de "infusão" como o de disciplina única têm resultados efectivos. Os autores concluem também que o conteúdo e a pedagogia do programa são preditores mais significativos das atitudes, dos sentimentos e das preocupações dos formandos face à Inclusão, do que o modelo de formação adoptado.

Usar modelos inclusivos para ensinar Educação Inclusiva aos professores está de acordo com um princípio de formação designado por “isomorfismo". Pretende-se, com esse princípio, acentuar que a formação deve seguir os mesmos valores e as mesmas práticas que se espera que o formando venha a adoptar quando for profissional. Não se pode pedir que um professor seja capaz de promover (ou pelo menos não entravar) a reforma inclusiva que deverá estar em curso nas escolas, se ele foi educado ou preparado em um modelo contrário a esse. Uma boa maneira de analisar e avaliar os programas de formação é discutir o quanto eles são real e eficazmente isomórficos face ao perfil do profissional que se pretende formar.

Em relação à Educação Física, esse perfil tem sido trabalhado em várias instâncias. Citamos o documento Standards for Initial Programs in Physical Education, publicado pela National Association for Sport and Physical Education dos Estados Unidos (NASPE, 2001). Entre as diferentes competências que os candidatos a professores de Educação Física devem ter, o documento aponta (Competência 3 - Alunos diferentes) que os professores de Educação Física compreendam as diferenças existentes na aprendizagem.

Os professores de Educação Física compreendem como os diferentes indivíduos diferem nas suas relações com a aprendizagem e criam um ensino apropriado adaptado a estas diferenças. Através deste perfil, os candidatos a professores demonstram a sua capacidade de planejar e desenvolver experiências de aprendizagem que são significativas para diferentes alunos e que permitirão aos estudantes desenvolver qualidades de respeito e responsabilidade definidas [...]. (NASPE, 2001, s.p., tradução nossa).

Resultados - os candidatos a professor deverão:

Práxis Educativa, Ponta Grossa, v. 12, n. 2, p. 317-333, maio/ago. 2017 Disponível em: < http://www.revistas2.uepg.br/index.php/praxiseducativa $>$ 
a) Identificar, seleccionar e desenvolver um ensino apropriado que seja sensivel às áreas fortes/fracas, às necessidades muiltiplas, aos estilos de aprendizagem e às experiências anteriores (por exemplo culturais, pessoais, familiares e comunitárias) dos alunos.

\section{b) Usar os serviços e recursos adequados para responder a diferentes necessidades de aprendizagem.}

Nessa mesma linha de competências dos professores de Educação Física para a Inclusão, iniciou-se, em 2007, um projecto europeu de Formação em Educação Física (European Inclusive Physical Education Training)", patrocinado pelo projecto europeu "Leonardo da Vinci". Esse projeto visou o desenvolvimento de onze competências que, mais tarde, foram assim apresentadas:

1. Adaptar o currículo de $\mathrm{EF}^{\dagger}$ da escola de forma a reflectir as condições actuais e as necessidades de todos os estudantes com NEE em EF.

2. Avaliar o nível efectivo de desempenho de estudantes com NEE em EF.

3. Planejar experiências de aprendizagem adequadas ao desenvolvimento em EFI.

4. Preparar a classe e a sala de aula para a Inclusão do aluno com NEE.

5. Adaptar o ensino para responder às necessidades de TODOS os alunos.

6. Gerir o comportamento dos alunos de forma a assegurar a aprendizagem mais apropriada e segura para TODOS os alunos.

7. Comunicar com os alunos com NEE e outros que estão directa ou indirectamente envolvidos no ensino da EFI.

8. Avaliar os progressos de alunos com NEE em EFI em relação com os seus próprios objectivos.

9. Avaliar a eficácia do programa de EFI.

10. Continuar a desenvolver as suas aptidões profissionais e conhecimento, bem como as dos outros.

11. Pugnar pelas necessidades e direitos dos alunos com NEE. (KUDLÁČEK; JESINA; FLANNAGAN, 2010, p. 16, tradução nossa).

Para desenvolver nos formandos esse conjunto de competências, um programa de

formação deve ser o mais isomórfico possível. Caso contrário, corre-se o risco de "transmitir informação" sem mudar comportamentos nem atitudes. Deve-se procurar não só fornecer as informações de forma expositiva, mas também comprometer os alunos em tipos variados de experiências que lhes permitam aprender do mesmo jeito que deverão ensinar.

\section{b) Dimensão dos conteúdos}

Em um estudo que realizamos sobre a análise dos programas das disciplinas de "Educação Especial" que eram lecionadas nos cursos de Educação Física de Universidades e Institutos Politécnicos portugueses, chegamos a constatações muito pouco estimulantes sob o ponto de vista inclusivo. Em primeiro lugar, há de ressaltarmos que todos os cursos de formação de professores de Educação Física dispunham de disciplinas sobre a área das pessoas com deficiência (o que, aliás, é obrigatório pela legislação portuguesa desde 1987). Tratavam-se de disciplinas de duração semestral com cerca de 40 horas de aulas presenciais e com títulos muito diferentes: "Desporto Adaptado", "Educação Física Especial", "Actividade Física Adaptada", "Actividade Motora Adaptada" etc. Entretanto, essas disciplinas davam realce sobretudo à caracterização (etiologia, incidência, comportamento típico) das pessoas com deficiência, estando os aspetos metodológicos bem menos presentes. Notava-se uma grande importância dada ao ensino do Desporto Adaptado, incluindo a classificação e a organização (nacional e internacional) do desporto para pessoas com deficiência, mas o que de fato saltava aos olhos era a ausência

\footnotetext{
${ }^{*}$ Disponível em: <www.eipet.eu>. Acesso em: 2 fev. 2010.

† EF= Educação Física; EFI = Educação Física Inclusiva; NEE = Necessidades Educativas Especiais.
} 
quase completa de conteúdos sobre, por exemplo, a adaptação de actividades, a aprendizagem multi-nível, a diferenciação curricular, os ambientes cooperativos, entre outros.

Esse exemplo poderá ser, pelo menos em Portugal, generalizado para outras áreas de formação. Continua a ser dado um grande realce à caracterização da diferença, como se essa fosse a chave para o futuro professor saber como educar alunos com condição de deficiência em contextos inclusivos. No entanto, saber o que é uma síndrome não é o mesmo que saber ensinar uma pessoa com essa síndrome, ainda mais em contextos inclusivos, com grupos e classes muito heterogéneos.

Outro aspecto interessante é a forma como são seleccionados os casos de alunos com condição de deficiência para estudo nos cursos de formação. É óbvio que uma formação nunca conseguirá proporcionar toda a informação necessária sobre todo o tipo de deficiência. Assim sendo, parece-nos que o mais indicado (o que nem sempre acontece) seria optar pelos tipos e pelas severidades de deficiência que encontramos com mais frequência nas escolas - vale frisar os casos com maior incidência são justamente os menos severos e com menor comprometimento.

Uma perspetiva ecológica de formação (no sentido de ser direcionada para todos os recursos da escola) permite realçar a importância das competências dos professores para negociar, para encorajar a cooperação e, sobretudo, para procurar uma coerência entre objetivos, práticas e tarefas (HASTIE; SIEDENTOP, 1999). Esses tipos de competências, juntamente as que permitem trabalhar em conjunto e pertinentemente com grupos muito heterogéneos, parecem ter de ser mais reforçadas nos cursos de formação de professores em geral e, em particular, de professores de Educação Física.

\section{c) Dimensão das estratégias de ensino}

Não é certamente suficiente o ensino expositivo para que determinados conteúdos sejam assimilados e colocados em prática. Jordan, Schwartz, McGhie-Richmond (2009), ao tratar da formação em Educação Inclusiva, indicam uma relação entre as crenças e a forma como essas crenças podem ser desenvolvidas por meio de práticas. Assim, as crenças sobre a deficiência poderão ser formadas, por exemplo, observando-se práticas docentes. Da mesma forma, as crenças sobre a capacidade dos alunos podem ser accionadas por intermédio do conhecimento e da observação de práticas relatadas ou realizadas por professores.

Quando revemos as teorias sobre os modelos de formação de professores, verificamos que existem diferentes paradigmas sobre como essa formação deve ser feita. Antes de mais, havia a ideia de que o professor deveria ser formado por meio da aquisição de determinados conhecimentos (paradigma "informativo"). Outras perspectivas foram surgindo, como as que realçam a importância de se desenvolver o "desempenho" profissional do professor (por intermédio, por exemplo, da auto ou hetero-observação) e as que realçam a importância da formação se centrar no "pensamento" do professor, confirmando que, sem atitudes e crenças adequadas, é pouco provável que qualquer conhecimento seja útil ou que qualquer ação pedagógica seja efectivamente adequada.

Vemos que as crenças estão ligadas a experiências práticas e, assim, talvez não seja necessário optar por uma destas perspectivas ("informação", "desempenho" ou "pensamento") e abandonar as outras. Certamente todas as experiências que valorizam a informação, o desempenho ou o pensamento do professor, bem como as experiências práticas que as acompanham, serão úteis para a sua formação. 
Seguindo ainda a ideia do isomorfismo apresentada acima, a questão que se pode colocar é de que forma as estratégias de formação usadas na formação de professores para a Inclusão são, elas próprias, inclusivas. Qual é a articulação feita entre a teoria e a prática nesses cursos?

$\mathrm{Na}$ verdade, se pensarmos no conjunto das estratégias de intervenção usadas em Educação Especial, podemos perguntar-nos quantas delas foram experimentadas pelos professores em formação. E damos exemplos: que experiências viveram os professores em formação sobre aprendizagem individualizada, aprendizagem cooperativa, trabalho de grupo (efectivo trabalho de grupo), trabalho de projecto, ensino preciso, etc. Muitas das estratégias que esperamos que os professores adoptem nunca foram por eles experimentadas como modelos eficazes e efectivos de aprendizagem. Lembramo-nos, por exemplo, da surpresa que os estudantes mostram quando trabalhamos com eles sobre a construção de uma unidade de ensino individualizada. Após determinarem o objectivo da unidade de aprendizagem, os estudantes planejam as actividades para grande grupo, para grupo de projecto, grupos de nível, pares e trabalho individual. Esta diversidade de enquadramentos permite-lhes descobrir que, afinal, é possível individualizar a aprendizagem e que este processo não tem nada a ver com o ensino individual ("de um para um"). Esse tipo de experiência é muito rico e, sobretudo, cimenta e alicerça nos futuros professores a convicção de que as estratégias de ensino, que são, por vezes, só conhecidas da literatura, afinal podem funcionar e ser úteis. A relação teoria-prática desempenha um papel fundamental no sucesso da formação. Jones (2009) afirma que, quando os professores encaram situações não habituais ou quando sentem que estão a ficar menos eficazes nas suas estratégias, é então que recorrem à investigação procurando respostas ou, pelo menos, alguma nova orientação. Assim, fica aqui evidenciada a importância dos estudantes não só conhecerem os resultados das investigações, mas também de terem ideias relativamente precisas sobre como estes resultados podem ser aplicados na prática.

Sintetizando: usar o princípio do isomorfismo na formação significa formar professores inclusivos por meio de modelos inclusivos de formação de professores.

\section{Educação Física e Inclusão: as promessas e as realidades}

Integrando o elenco das disciplinas que formam o currículo dos cursos do ensino fundamental, a Educação Física não pode ficar afastada do movimento de Educação Inclusiva. Pensar que a Educação Física poderia ficar alheia ou "participar com reservas" no movimento inclusivo contribuiria, sem dúvida, para fazer essa disciplina retornar a um estatuto de alguma menoridade que, nos últimos anos, tem vindo a ser superado.

É certo que existe algum descompasso entre as promessas e as realidades, no âmbito da Inclusão de pessoas com deficiência nas aulas de Educação Física (RODRIGUES, 2007). Na qualidade de uma disciplina predominantemente expressiva, a Educação Física parece, a princípio, ter fortes argumentos para poder ser um poderoso meio de promoção da Inclusão, por várias razões:

a) Pelo facto de ter um programa mais flexível que outras áreas curriculares e de poder acolher alunos com dificuldades sem a pressão do "programa da disciplina", espera-se que a Educação Física possa ser mais receptiva a programas curricularmente diferenciados.

b) Por incluir uma forte componente lúdica e de interacção social, a Educação Física contribui para a criação e o desenvolvimento de laços de pertença, solidariedade e cooperação, essenciais para a criação de um ambiente inclusivo.

Práxis Educativa, Ponta Grossa, v. 12, n. 2, p. 317-333, maio/ago. 2017 Disponível em: <http://www.revistas2.uepg.br/index.php/praxiseducativa > 
c) Por último, as actividades desenvolvidas nesse campo têm uma abrangência e uma mobilização de áreas mais globais do comportamento. A Educação Física, além de solicitar respostas ligadas ao desenvolvimento e ao desempenho motor, pode ainda mobilizar significativamente as áreas cognitivas, sociais e emocionais/afectivas. Essa abrangência constituiu uma mais-valia da Educação Física, na sua contribuição para o desenvolvimento humano.

Os professores de Educação Física têm aproveitado bem o potencial da área em que actuam, diversificando as suas formas de intervenção e encontrando estratégias que lhes permitem interagir adequadamente com classes heterogéneas. Hardin (2005) nota, por exemplo, que o trabalho em Educação Física com turmas étnica e culturalmente diversas, tem sofrido grandes avanços. No entanto, segundo esse mesmo autor, não se notam progressos semelhantes na formação dos professores de Educação Física no que diz respeito ao ensino de alunos com condição de deficiência. Essa falta de progressos verifica-se por meio de alguns factos:

a) A obrigatoriedade da participação nas aulas de Educação Física continua a ser menos rígida para alunos com deficiência do que para alunos sem deficiência. Quer dizer que, se um aluno tiver, por exemplo, dificuldades de Matemática, a escola mobilizar-se-á para que ele tenha apoio pedagógico e, eventualmente, algumas aulas suplementares. No entanto, se as dificuldades forem na área da Educação Física, a resposta mais frequente será a dispensa das aulas, em lugar de mais aulas ou de apoio acrescido. Dispensar o aluno das aulas de Educação Física é, na verdade, uma prática de exclusão.

b) As práticas docentes habituais em Educação Física encontram-se pouco relacionadas com valores inclusivos. Frequentemente, a competição e a procura da "técnica" perfeita limita a participação de todos os alunos: uns, incapazes de executar a técnica tal como é proposta; outros, desmotivados pela competição que valoriza sempre os mesmos aspectos do desempenho motor. Com isso, a organização das actividades motoras das aulas de Educação Física transforma-se em verdadeiros caminhos de exclusão. Tomemos o exemplo de uma aula standard de salto em altura: os alunos, à medida que não conseguem ultrapassar o sarrafo, vão sendo excluídos da actividade até sobrarem apenas os vencedores. Assim, a actividade desenrola-se inspirada nas competições desportivas oficiais e, como elas, quanto mais ela evolui, mais exclusão provoca (isto é, mais alunos sentados e inactivos). Esse aspecto não deixa de ser irónico, dado que, justamente os alunos a quem é proporcionada menos prática na actividade, seriam os que mais necessitavam de permanecer nela. Trata-se de um mero exemplo que, mesmo que não aconteça exactamente assim na generalidade das aulas de Educação Física, pode servir de inspiração para uma análise mais crítica das actividades que são propostas.

c) Finalmente, é criada uma prática de exclusão na Educação Física que vai mesmo para além das práticas de exclusão que a escola desenvolve. A escola já é, frequentemente, uma estrutura pouco inclusiva pela falta de acessibilidades, pela falta de flexibilização do currículo, pelos sistemas rígidos de avaliação, pelas reduzidas oportunidades de escolarização e socialização. A essas formas de exclusão, a Educação Física acrescenta ainda outras que são próprias da forma de desenvolver a sua actividade.

Assim, podemos considerar que a Educação Física, em muitos casos, em lugar de ser uma disciplina que contribui, acaba por constituir um obstáculo para a Inclusão, como é apresentado no Quadro 1 a seguir. 
Quadro 1 - Comparação entre a Educação Física Tradicional e a Educação Física Inclusiva

\begin{tabular}{|l|l|}
\hline \multicolumn{1}{|c|}{ Educação Física Tradicional } & \multicolumn{1}{c|}{ Educação Física Inclusiva } \\
\hline Valorização da homogeneidade & Valorização da diferença \\
\hline Competição & Cooperação \\
\hline Ensino de "técnicas" & Espaço para a criatividade \\
\hline Participação dependente do desempenho & Participação independente do desempenho \\
\hline Prática unidimensional (desportiva) & $\begin{array}{l}\text { Prática multidimensional } \\
\text { expressiva, cultural etc.) }\end{array}$ \\
\hline Relação treinador-praticante & Relação professor-aprendiz \\
\hline
\end{tabular}

Fonte: Moreira, Ferreira e Mendes (2012, p. 149).

Os professores de Educação Física, tal como os outros, são influenciados por factores que, em larga medida, ultrapassam a sua área disciplinar. Um desses factores (que é determinante) relaciona-se com as suas atitudes face à Inclusão. Sabe-se que essas atitudes, não sendo inatas ou imutáveis, dependem de um conjunto de factores como, por exemplo, o tipo e a severidade das condições de deficiência com que os professores lidam, a formação que receberam, os recursos postos à sua disposição, a sua idade ou género, entre outros (BRADSHAW; MUNDIA, 2006).

Em um estudo realizado com professores de Educação Física (MORLEY et al., 2005), sugere-se que as suas concepções sobre Inclusão se baseiem, antes de mais, na percepção que têm do nível de participação que os alunos com Necessidades Educativas Especiais podem atingir em aulas regulares. Esse nível de participação pode ser influenciado pela área da actividade proposta, pelo apoio recebido e pelas oportunidades de formação disponibilizadas para os professores. Os professores de Educação Física são, como os outros professores, influenciados pelas atitudes e pelas percepções sobre a Inclusão que compartilham com professores de outras áreas disciplinares.

Contudo, existe uma outra origem - esta exclusiva da área disciplinar de Educação Física - que, pelo valor que dá à técnica, à competição, à hierarquização e a um modelo baseado no desempenho, representa um segundo conjunto promotor de exclusão. Assim, a Educação Física possui uma dupla genealogia de exclusão (RODRIGUES, 2006) o que constitui um factor de maior dificuldade para cumprir as suas possibilidades, suas potencialidades e suas promessas como prática inclusiva.

Quando se analisa a contribuição da Educação Física para a Inclusão escolar de alunos, encontramos valores contraditórios. Goldwin e Watkinson (2000), ao analisarem um programa de Educação Física inclusivo com alunos com deficiências motoras, constataram esta mesma contradição: por um lado, encontraram sentido de pertença, participação adequada e partilha dos benefícios da actividade entre os alunos; por outro lado, encontraram, no mesmo grupo, isolamento social, dúvidas sobre a própria competência e participação restrita. A Educação Física encontra-se, assim, em uma encruzilhada entre as enormes possibilidades de contribuir para o processo de Inclusão e as dificuldades provenientes de uma prática tradicionalmente ligada aos valores competitivos do desporto. 


\section{A Inclusão na formação de professores de EF: um testemunho}

Um dos aspectos fundamentais da reforma dos cursos de formação de Professores de Educação Física é o valor que se dá a toda diferença, incluindo à diferença dos seus próprios formandos. Não uma diferença que é de alguns e que diminui, mas uma diferença que é característica de todos e que enriquece.

Um estudo feito por Carrington e Brownlee (2001) mostrou que a presença de um assistente com paralisia cerebral em aulas de formação de professores (pequenos e grandes grupos) foi considerada de grande valia para tornar mais positivas as atitudes dos formandos face à Inclusão. No contexto da EFI, a presença de uma pessoa com condição de deficiência, seja aluno ou professor, pode ser uma oportunidade ímpar para orientar a forma como a lição deve ser dada a todos os alunos e, mais especificamente, aos alunos com necessidades especiais.

Foi nesse sentido que recolhemos o testemunho da professora de Educação Física, Marta Rafael (M.R.). Trata-se de um excelente exemplo de como podemos aprender com as pessoas com condição de deficiência, se estivermos atentos. Com 32 anos de idade, Marta é atualmente professora de Educação Física na Escola Secundária [Ensino Médio] "António Nobre”, na cidade do Porto - Portugal. Apresentando brevemente o caso, aos 18 anos, quando havia terminado o $1^{\circ}$ ano da formação em Educação Física, Marta sofreu uma lesão medular incompleta ao nível C3-C4. Em termos funcionais, isso significa que Marta depende de cadeira de rodas para se locomover, tem a sensibilidade preservada e consegue realizar alguns movimentos abaixo do nível da lesão. Apresentamos, a seguir, excertos do seu testemunho publicado por Moreira, Ferreira e Mendes (2012, p. 151-154).

\section{Experiência como aluna de Licenciatura em Educação Física}

\section{Alterações ou adaptações realizadas pela Faculdade:}

O principal foi terem permitido que eu continuasse a Licenciatura. Como fui atleta de alta competição em Surf durante muitos anos e fui considerada uma excelente aluna, a Direç̧ão da Faculdade, em reunião com outros professores do curso, decidiram pela minha continuidade.

\section{Alterações ou adaptações realizadas pelos Professores:}

No curso em geral, permitiram que eu usasse o meu próprio computador portátil (porque estava mais habituada a ele), em vez de usar o da faculdade. Usava-o para escrever tudo: os trabalhos, as anotações e até fazer as avaliações.

Nas aulas práticas, eu assistia e apresentava sempre relatórios para que os professores conferissem se en tinha percebido bem ou se tinha ficado com dúvidas. Nos desportos colectivos, muitas vezes en era o árbitro; nos individuais, en fazia relatórios dizendo como deveriam ser dados os apoios... como posicionar as mãos para ajudar os alunos... Eu participava sempre das aulas, fosse de uma forma ou de outra.

\section{Uma semana "regular":}


De segunda a sexta-feira, entro na escola às $8 \mathrm{~h} 30 \mathrm{~m}$, 2 vezes por semana saio às $11 \mathrm{~h}$. e os outros 3 dias saio às $13 \mathrm{~b} 30 \mathrm{~m}$. Tenho todas as tardes livres, 3 delas com fisioterapia.

\section{Adaptações que ocorreram na escola e nas suas aulas:}

$\mathrm{Na}$ escola, construiram apenas mais uma ou duas rampas, porque já havia alunos cadeirantes. De resto, mais nada porque sou considerada um professor "normal" como todos os outros.

Quanto às alterações de maneira a que os alunos entendam aquilo que eu quero que eles façam, há várias coisas a referir. Por exemplo, na primeira aula, en converso muito, apresento o meu programa e, depois de lhes explicar as minhas limitações, procuro alertar que não é por eu estar em cadeira de rodas que as minhas aulas serão diferentes. Explico que, na maioria das vezes, os outros professores apenas "dizem" o que os alunos devem fazer e lembro-os que isso - falar ou dizer - eu também consigo fazer.

Depois, quando inicio um desporto que nunca tinha sido trabalbado com eles antes, eu primeiro dou uma aula teórica e recorro a muitas imagens - até porque, agora, há infinitos recursos de multimédia, com imagens, reportagens, filmes, artigos, revistas, que apresentam o desporto de uma forma melhor do que eu ou outro professor qualquer poderia mostrar. Às vezes, posso fazer o mesmo quando não consigo que eles entendam "o que" ou "como" é para fazer, mas é raro porque, no decorrer das aulas, eu vou corrigindo e chamando a atenção conforme aquilo que eles já tinham visto nas imagens.

\section{Reação dos alunos e outros professores:}

Houve um canal de televisão que fez. uma reportagem sobre o meu caso e, sem eu saber, perguntou isso aos alunos*. A resposta foi que, de inicio, eles pensaram: "Ai, meu Deus! Como é que vai ser?! Como é que esta professora vai dar as aulas?" Mas que, em pouco tempo, passaram a ver-me como uma professora normal, como todas as outras.

Quanto aos colegas, este ano uma professora também de Educação Física confidenciou-me que tinha muita curiosidade em ver como é que eu dava as aulas, porque não conseguia imaginar como seria. Depois que viu, achou a coisa mais normal do mundo: "tu dás aulas como eu dou, não bá diferença!", disse-me.

Eu acho que, num primeiro impacto, as pessoas devem pensar: "não é possivel". Depois de verem as turmas em funcionamento, percebem que as aulas decorrem normalmente.

\section{Mudanças nos alunos, por serem ensinados por uma professora em cadeira de rodas:}

\footnotetext{
*Entrevista "Venceu e é um exemplo". Disponível em: <http://www.youtube.com/watch?v=PjyER-c3IZg>. Acesso em: 22 out. 2016.
} 
Em primeiro lugar, eles se tornam muito mais autónomos. Por exemplo, no caso das coisas que en não consigo fazer, eles próprios tomam a iniciativa. Logo que chegam na aula, perguntam qual material é para buscar, onde os distribuir... Eu dou as ordens e eles já sabem o que fazer.

Em segundo lugar, tornam-se mais interdependentes, justamente nos casos onde eu não consigo dar as ajudas, mas tenho que garantir a segurança. Antes de lhes ensinar ginástica, por exemplo, dou uma aula onde só ensino como é que se dá a ajuda e friso muito bem que ninguém, ninguém mesmo, pode fazer nada sozinho sem ter um ou dois colegas a apoiar.

Noto, também, que há mais heterogeneidade e menos aqueles "grupinhos" de alunos. Claro que grupinhos sempre há mas, nas minhas aulas, eles têm obrigatoriamente que trabalhar em conjunto e, nas tarefas ou actividades, há sempre a Inclusão de um ou outro, que até não se dão muito bem, mas que acabam por ter que trabalhar juntos.

Em termos das atitudes ou dos comportamentos desses alunos, tendo convivido com uma pessoa assim como eu, com certeza que eles passaram a ver a vida de uma maneira um pouco diferente. Por exemplo, os alunos, em vez de aproveitarem o facto de en estar em cadeira de rodas e não respeitarem a autoridade que eu tenho ou coisa parecida, fazem exactamente o contrário. Mesmo as turmas com comportamentos mais complicados na opinião dos outros professores, comigo são extremamente respeitadoras.

\section{Melhor preparação para responder à diversidade:}

Acho que sim, por experiência própria. Afinal, a primeira pessoa com deficiência na aula sou eu. Se houver algum aluno que tenha alguma necessidade especial, acho que eu consigo facilmente fazer uma avaliação diferente e ajustar as minhas aulas para o aluno poder participar.

Há alunos com deficiência que ficam revoltados pelo facto de não lhes pedirem para fažer nada em Educação Física. Isso não é por má vontade dos professores mas, simplesmente, porque não fazem ideia que, em lugar de estar a proteger o aluno, o estão a excluir.

\section{Sugestões para a melhoria da formação de professores de Educação Física}

Uma sugestão seria investir nas aulas de Educação Física Adaptada, que nos podem dar algumas noções do que fazer para incluir todos os alunos nas nossas aulas.

Outro aspecto importante é a questão dos testes de acesso ao curso. Ingressar num curso de Educação Física depende de aprovação em testes físicos feitos para as pessoas saudáveis, ditas "normais". Agora que estou em cadeira de rodas, penso nas pessoas com deficiências muito menores que a minha, que dariam aulas perfeitamente, mas que reprovariam nos testes físicos. Não sugiro que estes testes sejam abolidos, mas talvez houvesse uma quota para pessoas com deficiência ou testes com um nivel de dificuldade consoante aquilo que cada um consegue fazer. Afinal, mesmo um aluno que tenha reprovado nestes testes físicos pode aprender a ser professor de Educação Física. Eu, se tivesse tido o acidente antes de entrar na Faculdade, não seria hoje professora de Educação Física!!! Em relação aos professores destes cursos, o que eu acho mesmo que o essencial é que eles tenham uma mente aberta. 
Quantas faculdades de Educação Física teriam abertura para reorganizar o seu currículo de forma a dar acesso e garantir o sucesso de um aluno com condição de deficiência? De fato, um testemunho dessa natureza faz-nos refletir e concluir que a condição de deficiência não impediu a professora de desenvolver todas as competências próprias de um professor de Educação Física bem-sucedido. Pelo contrário, a sua condição a motivou a adotar uma maior variedade de estratégias de ensino (ref.: audiovisuais), como também encorajou o surgimento de novas formas de interacção entre os alunos e destes com o professor. Nas suas aulas, a professora encorajou os alunos a serem responsáveis pela própria aprendizagem e pela aprendizagem dos colegas, tornando-os mais autónomos e, ao mesmo tempo, interdependentes, favorecendo interacções mais flexíveis entre todos. Vale notar que os comportamentos respeitosos dos alunos para com ela podem ter sido fortemente motivados pelas suas "atitudes inclusivas". Por fim, mas sem esgotar as possíveis reflexões, destacaríamos a importância de a professora ter colocado nos alunos a possibilidade de solução dos problemas de aprendizagem, em lugar de adotar pedagogias transmissivas - baseadas na "técnica" e no exemplo dado pelo professor.

\section{Síntese}

Ser professor implica adquirir e exercer um conjunto de competências em que a adaptação e a inovação estão sempre presentes. Perrenoud (2001) resgata o conceito de "habitus" ao falar do conjunto dos nossos esquemas de percepção, de avaliação, de pensamento e de acção que se tornam como que uma "estrutura estruturante", capaz de enfrentar uma grande diversidade de situações quotidianas, ao custo de acomodações menores. A formação de professores tem de ter em atenção a formação dessa estrutura de ação, capaz de dar ao futuro profissional uma determinada personalidade, mas também a capacidade de assimilar e acomodar novas situações.

As novas necessidades de formação de professores de Educação Física para poderem responder de forma inclusiva a classes naturalmente heterogéneas são um desafio para reformar os "antigos" sistemas de formação e questionar alguns dos valores mais arreigados da Educação Física. Sherborne (2001) escreveu que o seu método de Educação Motora se destinava a que cada criança se sentisse em casa com o seu corpo. A Educação Motora (ou, como normalmente se chama, a "Educação Física") tem esta nobre missão de usar a experiência corporal e o movimento para que a criança se sinta à vontade e feliz no seu corpo. Cada formador de professores deve pensar seriamente em quais opções de formação (modelos, conteúdos, experiências, etc.) deve assumir para que essas competências sejam desenvolvidas em todos os futuros professores, para que se sintam mais seguros e capazes de leccionar de forma não discriminatória e promovendo os valores da Educação Inclusiva

Esse é um desafio que vale a pena enfrentar para que a Educação Física represente um espaço em que seja promovida a aventura da aprendizagem, o prazer da partilha e a alegria do movimento.

\section{Referências}

BRADSHAW, L.; MUNDIA, L. Attitudes and concerns about inclusive education: Bruneian inservice and preservice teachers. International Journal of Special Education, v. 21, n. 1, p. 35-41, 2006. 
CARRINGTON, S.; BROWNLEE, J. Preparing teachers to support inclusion: the benefits of interaction between a group of pre-service teachers and a teaching assistant that is disabled. Teaching Education, v. 12, n. 3, p. 347-357, 2001. DOI: 10.1080/10476210120096597

GOLDWIN, D. L.; WATKINSON, E. J. Inclusive physical education from perspective of students with physical disabilities. Adapted Physical Activity Quarterly, n. 17, v. 2, p. 144-160, 2000. DOI: 10.1123 /apaq.17.2.144

HARDIN, B. Physical Education teacher's reflections on preparation for inclusion. Physical Educator, v. 62, n. 1, 2005.

HASTIE, P.; SIEDENTOP, D. An ecological perspective on Physical Education. European Physical Education Review, v. 5, n. 1, p. 9-30, 1999. DOI: 10.1177/1356336x990051002

JONES, M. A study of novice special educator's views of evidence-based practices. Teacher Education and Special Education, v. 32, n. 2, p. 101-120, 2009. DOI $10.1177 / 0888406409333777$

JORDAN, A.; SCHWARTZ, E.; MCGHIE-RICHMOND, D. Preparing teachers for inclusive classrooms. Teaching and Teacher Education, v. 25, n. 1, p. 535-542, 2009.

KOWALSKY, E. M. The infusion approach to teacher development. Journal of Physical Education Recreation and Dance, v. 66, n. 4, p. 49-54, 1995. DOI: 10.1080/07303084.1995.10608141

KUDLÁČEK, M.; JESINA, O.; FLANNAGAN, P. European Inclusive Physical Education Training. Advances in Rehabilitation, v. 3, n. 1, p. 14-17, 2010. DOI: 10.2478/v10029-0100003-6

LIMA-RODRIGUES, L. et al. Percursos de educação inclusiva em Portugal: dez estudos de caso. Lisboa: Fórum de Estudos de Educação Inclusiva, FMH, 2007.

MOREIRA, J.; FERREIRA, A. G.; MENDES, A. (Orgs.). Rumos pedagógicos da Educação Física em Portugal. Santo Tirso: De Facto, 2012.

MORLEY, D. et al. Inclusive physical education: teachers' views of including pupils with Special Educational Needs and/or disabilities: In Physical Education. European Physical Education Review, v. 11, n. 1, p. 84-107, 2005. DOI: 10.1177/1356336x05049826

NASPE. Standards for Initial Programs in Physical Education Teacher Education. 2001. Disponível em: <http://www.aahperd.org/naspe/standards/nationalStandards/>. Acesso em: 2 fev. 2010.

NATIONAL Education Steering Committee of the Moving to Inclusion Initiative. Moving to Inclusion: Active Living through Physical Education-Maximizing Opportunities for Students with a Disability (Introduction). Abridged version. Gloucester: Active Living Alliance for Canadians with a Disability, 1994.

ONU. Organização das Nações Unidas. Convenção sobre os direitos das pessoas com deficiência. Nova Iorque: ONU, 2006. 
PERRENOUD, P. O trabalho sobre o Habitus na formação de professores: análise das práticas e tomada de decisão. In: LÉOPOLD, P. et al. (Org.). Formando professores profissionais. Porto Alegre: Artmed, 2001.

RODRIGUES, D. As promessas e realidades da inclusão de alunos com necessidades especiais nas aulas de educação física. In: RODRIGUES, D. (Org.). Actividade motora adaptada: a alegria do Corpo. São Paulo: Artes Médicas, 2006.

RODRIGUES, D. Desenvolver a Educação Inclusiva: dimensões do desenvolvimento profissional. In: RODRIGUES, D. (Org.). Investigação em Educação Inclusiva. Lisboa: Fórum de Estudos de Educação Inclusiva, 2007. 2 v.

SHARMA, U.; FORLIN, C.; LOREMAN, T. Impact of training on pre-service teachers' attitudes and concerns about inclusive education and sentiments about persons with disabilities. Disability and Society, v. 23, n. 7, p. 773-785, 2008. DOI: 10.1080/09687590802469271

SHERBORNE, V. Developmental movement for children. London: Worth Pubs, 2001.

UNESCO. Organização das Nações Unidas para a Educação. Declaração de Salamanca. Conferência Mundial sobre Necessidades Educativas Especiais: Acesso e Qualidade. Salamanca: UNESCO,1994.

UNESCO. Organização das Nações Unidas para a Educação. Conclusions and recommendations of the 48th International Conference on Education. 2008. Disponivel em: <http://www.ibe.unesco.org/en/ice/48th-ice-2008.html>. Acesso em: 14 fev. 2017.

VICKERMAN, P. Training physical education teachers to include children with special educational needs: perspectives from physical education initial teacher training providers. European Physical Education Review, v. 13, n. 3, 2007. DOI: 10.1177/1356336x07083706

Recebido em 31/05/2016

Versão corrigida recebida em 09/03/2017

Aceito em 10/03/2017

Práxis Educativa, Ponta Grossa, v. 12, n. 2, p. 317-333, maio/ago. 2017 Disponível em: <http://www.revistas2.uepg.br/index.php/praxiseducativa $>$ 